\title{
Social Representations and the Construction of Teachers' Professional Identity: A Case Study at IBqM - UFRJ.
}

\author{
VELLOSO, A., LANNES, D. \\ Instituto de Bioquímica Médica, Universidade Federal do Rio de Janeiro, \\ Rio de Janeiro - RJ - Brasil
}

In Brazil the two groups of teachers, upper- and lower-level teachers, have since followed different trajectories, despite having the same profession This study of how teachers' personal and collective identities are constructed was undertaken with a view to delineating and defining the professional and social significance of being a teacher. The sample was 41 university professors, 46 doctoral students and 74 school teachers associated with IBqM/UFRJ. These groups were examined with respect to their social representations (SR) about "teacher", the influence of their educational background and their performance in the classroom. The SR of the university professors and graduate students were similar, and centered on the themes of teaching and knowledge. In contrast, the SR of the school teachers were defined by dedication and tolerance. During the narrative of school background, all the subjects consider, themselves, as a mirror of what they lived in Basic Education. The majority referred to personal characteristics of their "best teachers". The preference for a particular teacher seems to have great influence of the affective aspects. However, their lessons are very distant of their individual models of "best teachers". The legacy of the "school chairs", can be seen in the reproduction of the traditional pedagogical pattern of the eighteenth century (Pedagogism).

Keywords: Social Representations, Identity, Teachers and Graduate Students 